\title{
Risk factors to hospital mortality valvar reoperations
}

\author{
Fatores de risco para mortalidade hospitalar nas reoperações valvares
}

Carlos Manuel de Almeida BRANDÃO, Pablo Maria Alberto POMERANTZEFF, Luciano Rapold SOUZA, Flávio TARASOUTCHI, Max GRIMBERG, Sérgio Almeida de OLIVEIRA

RBCCV 44205-608

\section{Abstract:}

Objective: Analyze the risk factors for hospital mortality in valvar reoperations.

Method: A prospective analysis was performed of 194 patients that underwent valvar reoperations between July 1995 and June 1999. The following variables were analyzed: gender, age, functional class, number and type of previous operations, cardiac rhythm, urgency at operation, creatinine level, left ventricular ejection fraction, left ventricular systolic and diastolic diameters, right ventricular systolic pressure, prothrombin activity, activated partial thromboplastin time relation, platelet count, cardiopulmonary bypass time, aortic cross-clamp time, number and position of valves, type of procedure, associated procedures and intraoperative bleeding volume. Univariate and multivariate statistical analyses were performed to determine the risk factors for hospital mortality.

Results: The overall hospital mortality was $8.8 \%$ (17 patients). Univariate analysis showed that the following variables were associated with higher mortality rates: advanced New York Heart Association functional class, decreased left ventricular ejection fraction, decreased prothrombin activity, increased creatinine level, longer aortic cross-clamping time, prolonged cardiopulmonary bypass time, concomitant associated procedures, and higher intraoperative bleeding volume. Logistic multivariate analysis identified advanced New York Heart Association functional class, creatinine level higher than $1.5 \mathrm{mg} / \mathrm{dl}$, and cardiopulmonary bypass time longer than 120 minutes as independent predictors of hospital mortality.

Conclusions: The variables functional class IV, creatinine level $>1.5 \mathrm{mg} / \mathrm{dl}$ and cardiopulmonary bypass time $>120 \mathrm{~min}$ were independent predictors of hospital mortality in valvar reoperations.

Descriptors: Heart valves, surgery, risk factors.

\section{Resumo}

Objetivo: Identificar fatores de risco para mortalidade hospitalar em reoperações valvares.

Método: Foi realizada análise prospectiva de 194 pacientes submetidos a reoperações valvares no período entre julho de 1995 e junho de 1999. As variáveis estudadas foram: sexo, idade, classe funcional, número e tipo de operações prévias, intervalo entre as operações, caráter da operação, creatinina sérica, fração de ejeção do ventrículo esquerdo, diâmetros diastólico e sistólico do ventrículo esquerdo, pressão sistólica de ventrículo direito, atividade de protrombina, relação do tempo de tromboplastina parcial ativada, contagem de plaquetas, tempo de circulação extracorpórea, tempo de pinçamento aórtico, posição e número de valvas, tipo de procedimento, operações associadas e volume de sangramento intra-operatório. Análise univariada e multivariada foi realizada para determinar os fatores de risco para mortalidade hospitalar.

Resultados: A mortalidade hospitalar foi de $8,8 \%$ (17 pacientes). A análise univariada identificou as seguintes variáveis associadas a maior mortalidade: classe funcional avançada, fração de ejeção do ventrículo esquerdo baixa, atividade de protrombina baixa, creatinina elevada, tempo de circulação extracorpórea prolongado, tempo de pinçamento aórtico prolongado, procedimentos associados e volume de sangramento intra- operatório elevado. Na análise multivariada foram significativas: classe funcional IV, creatinina $>1,5 \mathrm{mg} / \mathrm{dl}$ e tempo de circulação extracorpórea > 120 minutos.

Conclusões: As variáveis classe funcional IV, creatinina > $1,5 \mathrm{mg} / \mathrm{dl}$ e tempo de circulação extracorpórea $>120$ minutos são fatores de risco independentes para mortalidade hospitalar nas reoperações valvares.

Descritores: Valvas cardíacas, cirurgia. Fatores de risco.

Work performed in Instituto do Coração of Hospital das Clínicas of the Medical School, University of São Paulo. São Paulo, Brazil.

Presented at the $28^{\text {th }}$ National Cardiac Surgery Congress, Ouro Preto, MG, 5th to

7th April, 2002.

* Instituto do Coração of Hospital das Clínicas of the Medical School, University of São Paulo.

Correspondence address: Carlos Manuel de Almeida Brandão. Av. Dr. Enéas de Carvalho Aguiar, 44. Cerqueira César. São Paulo, SP, Brazil. CEP: 05403-000. Tel: (11) 30695638. Fax: (11) 30695415.

E-mail:carlos.brandao@incor.usp.br 


\section{INTRODUCTION}

Patients submitted to valvar reoperations make up a very heterogeneous group, since they include patients with structural dysfunction of bioprostheses or valvar restenosis, endocarditis in prostheses, para-valvar escape or mechanical prosthesis thrombosis. These patients present a variety of clinical conditions, that can be asymptomatic, oligosymptomatic or are even suffering from cardiogenic shock. Surgical intervention in reoperation demands technical accuracy and special care, essential for good results.

In our area, the number of valvar reoperations is big, due mainly to the ample utilization of bioprostheses that have a life span limited by structural dysfunction. In the period from 1980 and 1999, at the Instituto do Coração, among 7,544 valvar operations, 5,502 prostheses were implanted, with 4,535 bioprosthesis, corresponding to $82.4 \%$. Of these operations, $22.8 \%$ were reoperations.

In international literature, various univariate $[1,2]$ and multivariate analyses have been carried out identifying risk factors of hospital morbidity and mortality. Few works in our area $[5,6]$ have analyzed risk factors of valvar reoperations, and there have been no multivariate analysis of these factors, something that has not clearly identified independent risk factors of the mortality in this population.

The objective of the present work, is to identify risk factors of hospital mortality in patients submitted to valvar reoperations at the Instituto do Coração of the Medical School of the University of São Paulo.

\section{METHOD}

In the period from July 1995 to June 1999, a prospective analysis of 194 consecutive patients submitted to valvar reoperations was effected. Only patients with a history of valvar operations were included in this study.

The indication of reoperation was bioprosthesis structural dysfunction in 129 patients $(66.5 \%)$, calcification in 59 and rupture in 70; dysfunction of a mechanical prosthesis in 9 patients $(4.6 \%)$; out of which 1 had thrombosis of the prosthesis and 8 had para-valvar escape; endocarditis in prosthesis in 13 patients (6.7\%); endocarditis in native valve in 1 patient $(0.8 \%)$, restenosis in native valve in 32 patients $(16.5 \%)$ and post-plastic mitral insufficiency in 10 patients $(5.1 \%)$. The etiology of the primary valvar lesion was rheumatic fever in 146 patients $(75.3 \%)$, degeneration in $20(10.3 \%)$, endocarditis in $14(7.2 \%)$, congenital in $12(6.2 \%)$, dilated cardiomyopathy in $1(0.5 \%)$ and trauma in $1(0.5 \%)$.

The interval between the operations ranged from 1 month to 43 years, with average of $8.1 \pm 6.2$ years. Valvar replacements were performed in 178 patients $(91.7 \%)$, with utilization of bioprosthesis in $144(74.2 \%)$ and mechanical prosthesis in $34(17.5 \%)$. Sixteen patients underwent conservative procedures.

Seventy-seven patients (36.7\%), older than 40 years or with risk factors to coronary disease, went through cineangiocardiography and critical coronary lesions were identified in 3 patients (1.5\%). These were submitted to coronary artery bypass grafting with saphenous vein graft, all coincidentally to the right coronary artery. In 6 patients (3.1\%) with endocarditis we found aortic valvar ring abscesses, which were treated through direct suture in 5 patients $(2.6 \%)$ and through reconstruction with bovine pericardium flap in 1 patient $(0.5 \%)$. In 1 patient $(0.5 \%)$, we found a mitral valvar ring abscess, which was treated by direct suture.

Access was gained via median sternotomy, performed with a circular-oscillating saw. The left pleura was systematically opened, allowing adequate mobilization of the heart. We continued with the dissection of the right atrium and of the aorta. Cardiopulmonary bypass was established through the catheterization of the ascending aorta and of the superior and inferior cava veins. Myocardial protection was performed through moderate hypothermia at $28^{\circ} \mathrm{C}$ associated with topical hypothermia and St. Thomas type crystalloid cardioplegic solution every 25 minutes, via anterograde. For patients who already had prosthesis, removal was effected by withdrawing the previous suture threads allowing traction of these prostheses with Mayniham type forceps and their progressive separation from the valvar ring. After removal of the prosthesis, the excess of fibrosis or remnants of tissues of the previous implants were systematically removed from the valvar ring.

\section{Pre-operative variables}

The following clinical variables were analyzed: gender, age, functional class (FC), number of previous operations, type of previous operation, heart rhythm and character of the operation.

A hundred and twenty-four patients (63.9\%) were female and $70(36.1 \%)$ were male. Ages ranged from 6 to 83 years old, average $47.4 \pm 17.3$ years old. For the purpose of risk analysis, they were divided into the following age brackets: under or 16 years old (15 patients), from 17 to 65 years old (144 patients) and over 65 years old ( 35 patients). The FC in 20 patients (10.3\%) was FC II, $104(53.6 \%)$ it was FC III and $70(36.1 \%)$ it was FC IV.

The average number of previous valvar operations was $1.4+0.7 ; 127(65.5 \%)$ patients had undergone $1 ; 52$ patients $(26.8 \%)$ had undergone $2 ; 13$ patients $(6.7 \%)$ had undergone 3 ; and 1 patient $(0.5 \%)$ had undergone 5 previous valvar operations. According to the type of previous valvar operation, $43(22.2 \%)$ patients had been submitted to conservative surgeries and $151(77.8 \%)$ to valvar replacements.

A total of 126 (64.9\%) patients presented sinus rhythm, $67(34.5 \%)$ presented atrial fibrillation and $1(0.5 \%)$ showed total atrioventricular blockade with a universal 
atrioventricular pacemaker. Five operations (2.6\%) were performed in an emergency situation and all the remainder was elective. The indication of emergency was acute pulmonary edema in 4 patients and septic shock in one.

The following doppler echocardiographic parameters were analyzed: left ventricle ejection fraction (LVEF), left ventricle diastolic diameter (LFDD), left ventricle systolic diameter (LVSD) and right ventricle systolic pressure (RVSP), all of which were stratified in accordance with normal or altered valves. LVEF varied from 29 to $85 \%$, with an average of $68.4 \pm 9.3 \%$; LFDD ranged from 3.4 to $10.7 \mathrm{~cm}$, with a mean of $5.4 \pm 0.9 \mathrm{~cm} ; L V S D$ varied from 2.1 to $8.5 \mathrm{~cm}$, with an average of $3.6 \pm 0.8$ centimeters. RVSP varied from 20 to 120 $\mathrm{mmHg}$, with an average of $56.9 \pm 19.9 \mathrm{~mm} \mathrm{Hg}$.

The following laboratory variables were analyzed: creatinine serous level, activity of prothrombin (AP), activated partial thromboplastin time relation (APTTr) and platelet count, which were divided according to normal or altered values, as per the measurement methods utilized. Creatinine varied from 0.4 and $2.3 \mathrm{mg} / \mathrm{dL}$, with an average of $1.0 \pm 0.3 \mathrm{mg} / \mathrm{dL}$. AP varied from 24.4 to $100 \%$, with an average of $77.2 \pm 16.7 \%$. APTTr was from 0.6 to 2.4 , with a mean of $1.1 \pm 0.2$. The platelet count ranged from 67,000 to $380,000 /$ $\mathrm{mm} 3$, with an average of $194,902 \pm 63,459 / \mathrm{mm} 3$.

\section{Intra-Operative Variables}

The following intra-operative variables were analyzed: cardiopulmonary bypass time, aortic cross-clamping time, the number of valves, the type of procedure, the position, associated operations and the volume of intra-operative bleeding.

Cardiopulmonary bypass time varied between 34 and 247 minutes, with an average of $110.6 \pm 34.6$ minutes. The patients were divided in two groups: with cardiopulmonary bypass time less than or equal to 120 minutes (134 patients) and more than 120 minutes (60 patients). The aortic crossclamping time was from 22 to 214 minutes (average $91.2 \pm$ 31.3 minutes), the patients were divided into: less than or equal to 90 minutes (115 patients) and more than 90 minutes (79 patients).

The volume of intra-operative bleeding varied between 1.1 and $52.0 \mathrm{ml} / \mathrm{Kg}$ of weight. For risk analysis, we split the patients into two groups, according to the mean bleeding value $(8.6 \mathrm{ml} / \mathrm{Kg}$ ): less than or equal to $8.6 \mathrm{ml} / \mathrm{Kg}$ (120 patients) and more than $8.6 \mathrm{ml} / \mathrm{Kg}$ (74 patients).

A total of 121 patients $(62.4 \%)$ had 1 valve approached, $55(28.3 \%) 2$ valves and $18(9.3 \%) 3$ valves. Sixteen patients (8.2\%) underwent conservative operations, 144 (74.2\%) underwent bioprosthesis implantations and 34 (17.5\%) underwent implantations of mechanical prostheses.

The mitral valve was treated in 73 patients (37.6\%), aortic in 45 (23.2\%); mitral and aortic in 32 (16.5\%); mitral and tricuspid in 23 (11.8\%); mitral, aortic and tricuspid in $18(9.3 \%)$; tricuspid in $2(1.0 \%)$ and aortic and tricuspid in $1(0.5 \%)$. Seven patients (3.6\%) underwent surgical treatment of ring abscesses and $3(1.5 \%)$ underwent coronary artery bypass grafting.

\section{Statistical Analysis of Data}

To assess the predictive factors of the occurrence of death, an association of the pre- and intra-operative variables with mortality was made, using univariate analysis and the Pearson Qui-squared test, or the Fisher exact test, for variables with low frequencies.

After, the selected variables in this analysis were used for the adjustment of logistic regression models, [7] to assess which variables were more strongly associated to the probability of death. The level of significance for analysis was $5 \%$, and all the calculations were made by means of the Statistical Analysis System. [8]

Death was considered as having occurred on any postoperative day during the hospital stay.[9]

\section{RESULTS}

Hospital mortality was $8.8 \%$ (17 patients). The main cause of mortality at hospital was low cardiac output in 6 patients (35.3\%). Other causes were multiple organ failure in 5 patients $(29.4 \%)$, sepsis in $3(17.6 \%)$, adult respiratory distress syndrome (ARDS) in $1(5.9 \%)$, stroke in $1(5.9 \%)$ and a coagulation disorder in 1 patient $(5.9 \%)$.

\section{Univariate Analysis}

The variables FC, LVEF, creatinine serous level, AP, bypass time, aortic cross-clamping time, associated operations and bleeding volume were predictive of hospital mortality. (Table 1)

Table 1. Univariate Analysis: significant variables

\begin{tabular}{lllll}
\hline Variable & Patients & Mortality & $\%$ & p-value \\
\hline FC & 7 & & & \\
II & 20 & & & \\
III & 104 & 4 & 3.8 & $<0.001$ \\
IV & 70 & 13 & 18.6 & \\
LVEF & & & & \\
$\leq 65 \%$ & 55 & 10 & 18.2 & 0.003 \\
$>65 \%$ & 139 & 7 & 5.0 & \\
Creatinine & & & & \\
$\leq 1.5$ mg/dL & 179 & 12 & 6.7 & 0.005 \\
$>1.5 \mathrm{mg} / \mathrm{dL}$ & 15 & 5 & 33.3 & \\
AP & & & & \\
$\leq 60 \%$ & 32 & 6 & 18.7 & 0.028 \\
$>60 \%$ & 162 & 11 & 6.8 & \\
BT & & & & \\
$\leq 120 \mathrm{minutes}$ & 134 & 6 & 4.5 & 0.002 \\
$>120 \mathrm{minutes}$ & 60 & 11 & 18.3 & \\
Aortic Cross-clamping Time \\
$\leq 90 \mathrm{minutes}$
\end{tabular}

FC: functional class; LVEF - left ventricle ejection fraction; AP activity of prothrombin; BT - cardiopulmonary bypass time. 
Gender did not influence mortality significantly, although it was higher in the women $(10.5 \%)$ than in men (4.7\%). Age was not predictive of mortality either, death was absent in under 16-year-old patients, $9.0 \%$ in patients from 17 to 65 years old and $11.4 \%$ in patients over 65 . The number of previous operations did not interfere significantly, although it was higher in the first reoperation $(10.3 \%)$ than in the second $(5.9 \%)$ or the third one $(6.7 \%)$. There was no mortality in the fourth or fifth reoperations. Patients with previous conservative operations had a $2.3 \%$ mortality rate, against $10.6 \%$ in the patients with previous valvar replacements. The heart rhythm and the character of the operation were not predictive of hospital mortality, either.

The Doppler echocardiographic variables LFDD, LVDS and RVSP and laboratory variables APTTr and also the platelet count of did not influence significantly hospital mortality.

The number of valves was not predictive of mortality, although it was lower in the patients with 1 valve $(5.8 \%)$, than in those with $2(14.5 \%)$ or 3 valves $(11.1 \%)$. The type of procedure was not a risk factor either, mortality was absent in conservative procedures, $2.9 \%$ in the implantation of mechanical prostheses and $11.1 \%$ in the implantation of bioprosthesis. Mortality was seen in $2.7 \%$ of mitral valve patients, $8.9 \%$ of aortic valve patients $9.4 \%$ of mitral-aortic valve patients, $21.7 \%$ of mitral-tricuspid valve patients, $11.1 \%$ of mitral-aortic-tricuspid valve patients and $33.3 \%$ of the remaining associations.

\section{Multivariate analysis - logistic regression}

Considering the pre- and post-operative variables that presented significance in the univariate analysis, logistic regression was adjusted to assess the importance of such variables, on the occasion of hospital death. In Table 2 the results of this adjustment are presented.

Table 2. Logistics Regression: independent variables.

\begin{tabular}{llllll}
\hline EFFECT & ESTIMATE & SE & P-value & OR & CI 95\% \\
\hline Creatinine $>1.5 \mathrm{mg} / \mathrm{dL}$ & 1.8057 & 0.7024 & 0.010 & 6.084 & $(1.536 ; 24.105)$ \\
FC IV & 1.7030 & 0.6185 & 0.006 & 5.490 & $(1.634 ; 18.454)$ \\
BT $>120 \mathrm{~min}$ & 1.3935 & 0.5725 & 0.015 & 4.029 & $(1.312 ; 12.374)$ \\
Interception & -4.1865 & 0.6318 & $<0.001$ & & \\
\hline
\end{tabular}

FC - functional class; BT - cardiopulmonary bypass time; SE - Standard Error OR - Odds Ratio; CI - confidence interval

\section{COMMENTS}

The number of valvar reoperations has increased in the last few years due to several factors. These include: longer survival after valvar operations, increasing life expectancy of the population and wide utilization of bioprosthesis in the population, which, in view of its productive life limited by structural dysfunction, require new surgical interventions. In our casuistic, $66.5 \%$ of the patients presented rupture or calcification of bioprosthesis.

Hospital mortality in valvar reoperations, in general, is considered higher than mortality of first operations. In this series, global mortality was $8.8 \%, 2.7 \%$ for the mitral valve and $8.9 \%$ for the aortic valve. ANTUNES \& MAGALHAES [10] describe $12 \%$ mortality for reoperations of mitral prosthesis and ANTUNES [11] describes 9\% for aortic prosthesis. JAMIESON et al., [12] in a multicenter study from the Database Committee of the Society of Thoracic Surgeons, analyzed 86,580 patients submitted to valvar operations between 1986 and 1995, with mortality rates of $5.9 \%$ for elective aortic reoperations and $6.2 \%$ for elective mitral reoperations. In our group, BARROZO et al. [13] described $9.89 \%$ of hospital mortality in 697 patients who underwent valvar reoperations.

Pre-operative FC is, undoubtedly, an important predictor of hospital mortality. Several authors [14-16] identified FC IV as an independent predicting factor of mortality. According to HUSEBYE et al., [17] in an analysis of 552 valvar reoperations performed at the Mayo Clinic, hospital mortality was significantly higher in FC IV. They recommended that, when a significant prosthetic dysfunction is diagnosed, surgical intervention is to be assigned, even in oligosymptomatic patients, in order to minimize the operative risk and to improve late survival.

LVEF was an independent risk factor in hospital mortality. BORTOLOTTI et al.[1] demonstrated that patients who survived the immediate post-operative period, had significantly bigger LVEF. TURINA \& TURINA [18] did not show statistically significant differences among patients with LVEF lower and higher than $50 \%$.

Serous creatinine also considerably influenced hospital mortality. BIGLIOLI et al., [4] in an univariate analysis of continuous variables, identified the serous creatinine level as predictive of hospital mortality, in agreement with our results. AKINS et al. [19] demonstrated the influence of preoperative renal failure in the hospital morbidity and mortality, an independent predictive factor in the multivariate analysis, as was also presented by PIEHLER et al. [14]

AP was also, a predictive factor of hospital mortality in the univariate analysis. AP alterations show depletion of dependent vitamin $\mathrm{K}$ factors, mainly with factor $\mathrm{V}$ at normal levels. There are no reports in the literature correlating AP with hospital mortality.

Cardiopulmonary bypass time greatly influenced hospital mortality in a multivariate analysis. This risk factor was also described by several authors, such as BIGLIOLI et al. [4] and CAUS et al. [20] The long cardiopulmonary bypass time is related to other factors, such as prolonged operations, 
multiple valvar operations, ring reconstruction in endocarditis with ring abscesses, or patients with ventricular dysfunction, who need circulatory care for a longer period. The aortic cross-clamping time was also predictive of hospital mortality, giving support to various works in the literature, as in the case of BIGLIOLI et al. [4] and PANSISI et al. [16] This is a variable which is also directly related to the technical complexity of the operation.

The presence of associated operations was also predictive of hospital mortality in the univariate analysis, as was reported by BORTOLOTTI et al., [1] PIEHLER et al. [14] and RIZZOLI et al. [15] In our series, the association with the surgical treatment of the valvar ring abscess was responsible for this result. The valvar ring abscess is a disease associated with high hospital morbidity and mortality, as demonstrated by LYTLE et al. [21] and POMERANTZEFF et al. [22]

The volume of intra-operative bleeding was also a mortality predictive factor in the univariate analysis. This variable has not been described in the literature, as predictive of hospital mortality and is not an independent variable.

In relation to gender, our results were similar to those described by COHN et al. [23] and ANTUNES, [24] who did not find influence of gender on hospital mortality. Age was not a predictive factor either of mortality. Some authors, like PIEHLER et al., [14] identified age as an independent factor of hospital mortality in valvar reoperations.

Although mortality was greater in the first rather than in the second or third reoperation, this difference in the previous number operations was not statistically significant. In the series presented by PIEHLER et al., [14] either the number of previous heart operations or the number of previous valvar operations was predictive of mortality in the multivariate analysis.

Patients with previous conservative operations presented a hospital mortality of $2.3 \%$, while those who underwent previous valvar replacements, had a mortality rate of $10.6 \%$; however, this difference was not statistically significant. A similar result was presented by LYTLE et al., [3] which reinforces the indication of conservative valvar procedures, whenever possible.

Atrial fibrillation can be a risk factor of hospital mortality, as it can provoke low cardiac output in the post-operative period or predispose patients to thromboembolic accidents. In the literature, atrial fibrillation is identified as a risk factor in valvar operations. [25] In our series, as well as in that of ANDRADE et al., [26] atrial fibrillation did not statistically influence mortality hospital.

Several authors, such as BORTOLOTTI et al., [1] BIGLIOTI et al., [4] RIZZOLI et al., [15] PANSISI et al., [16] HUSEBYE et al. [17] and AKINS et al., [19] identified the emergency character of valvar reoperations as an independent predictive factor of mortality. In our series, mortality was absent in emergency reoperations, but this situation related to only 5 cases.

The LFDD and LVSD did not influence hospital mortality, as reported by BIGLIOLI et al. [4] According to CARABELLO et al., [27] the only independent predicting factor of bad evolution after valvar operation is the systolic volume rate. The hospital mortality did not suffer significant RVSP influence, either. In the multivariate analysis presented by BIGLIOLI et al., [4] the value of the pulmonary artery pressure did not influence mortality significantly. A similar result was obtained by AKINS et al., [19] who analyzed the systolic pressure of the pulmonary artery.

Other alterations in the coagulation examinations such as APTTr and the platelet count were not identified as risk factors of hospital mortality, although mortality was higher in patients with these alterations.

The number of approached valves was not predictive of hospital mortality either. This variable was identified as a risk factor of mortality in other series of the literature. $[14,16]$ The position was not a predictive factor of mortality either, although it was lower in the mitral position. ROSSITER et al. [28] suggested that the disparity between the aortic and mitral positions, can be explained by the higher occurrence of endocarditis in prosthesis in the aortic position. On the other hand, LYTLE et al. [3] associated these results to the greater association of the coronary arterial disease in the aortic position. The type of procedure performed did not influence mortality significantly, with $11.1 \%$ for the replacement by bioprosthesis, $2.9 \%$ for the replacement of mechanical prostheses and $0 \%$ in conservative procedures.

$\mathrm{COHN}$ et al. [23] demonstrated the importance of the improvement of the technique for the results in the valvar reoperations. According to these authors, some alterations in the operative technique have contributed to the improvement of the results. These include the more frequent utilization of cardiopulmonary bypass via femoro-femoral, systemic hypothermia, sanguineous cardioplegia, monitoring in the post-operative period of the artery and pulmonary capillary pressures and of the central venous pressure, the use of a provisional atrial and ventricular pacemaker and the use of automatic intra-operative selftransfusion.

Another aspect highlighted in the literature, is the precocious indication of surgery in oligosymptomatic or asymptomatic patients $[29,30]$ with structural dysfunction of prosthesis. This avoids that such patients require operations in advanced functional class or in emergency conditions.

To sum up, the upgrading of techniques, the individual analysis of each case, with special attention to risk factors, to better prepare the patients in the pre-operative period, or to precociously indicate operations, are of fundamental importance to gain good results in valvar reoperations. 


\section{CONCLUSIONS}

The FC IV, the serous creatinine level $>1.5 \mathrm{mg} / \mathrm{dL}$, the LVEF $<65 \%$, the AP $<60 \%$, the cardiopulmonary bypass time $>120$ minutes, the time of aortic cross-clamping $>90$ minutes, the associated operations and the bleeding volume $>8.6 \mathrm{ml} / \mathrm{Kg}$, were risk factors predicting hospital mortality in the univariate analysis.

The FC IV, the serous creatinine level $>1.5 \mathrm{mg} / \mathrm{dL}$ and the cardiopulmonary bypass time $>120$ minutes, were identified as predicting risk factors independent of hospital mortality in the multivariate analysis.

\section{BIBLIOGRAPHIC REFERENCES}

1. Bortolotti U, Milano A, Mossuto E, Mazzaro E, Thiene G, Casarotto D - Early and late outcome after reoperation for prosthetic valve dysfunction: analysis of 549 patients during a 26- year period. J Heart Valve Dis 1994; 3: 81-7.

2. Sener E, Yamak B, Katircioglu SF et al. - Risk factors of reoperations for prosthetic heart valve dysfunction in the ten years 1984- 1993. Thorac Cardiovasc Surg 1995; 43: 148-52.

3. Lytle BW, Cosgrove DM, Taylor PC et al. - Reoperations for valve surgery: perioperative mortality and determinants of risk for 1000 patients, 1958- 1984. Ann Thorac Surg 1986; 42: 632-43.

4. Biglioli PDI, Matteo S, Parolari A, Antona C, Arena V, Sala A - Reoperative cardiac valve surgery: a multivariable analysis of risk factors. Cardiovasc Surg 1994; .2: 216-22.

5. Pomerantzeff PMA, Yochitomi Y, Fabri HA et al. - Reoperações valvares: experiência do InCor- FMUSP. Rev Bras Cir Cardiovasc 1991; 6: 182-9.

6. Bueno RM, Neto VA, Melo RFA - Fatores de risco em operações valvares: análise de 412 casos. Rev Bras Cir Cardiovasc 1997; 12: 348-58.

7. Hosmer Jr DW, Lemeshow S - Applied logistic regression. John Wiley \& Sons, 1976: 75-118.

8. SAS Institute Inc., SAS/STAT ®User's Guide. Version 6. Fourth Edition. Volumes 1,2. Cary, NC: SAS Institute Inc., 1989.

9. Edmunds Jr LH, Clark RE, Cohn LH, Grunkemeier GL, Miller DC, Weisel RD - Guidelines for reporting morbidity and mortality after cardiac valvular operations. J Thorac Cardiovasc Surg 1996; 112: 708-11.
10. Antunes MJ, Magalhães MP - Isolated replacement of a prosthesis or a bioprosthesis in the mitral valve position. Am J Cardiol 1987; 59: 346-9.

11. Antunes MJ - Isolated replacement of a prosthesis or a bioprosthesis in the aortic valve position. Am J Cardiol 1987; 59: $350-2$.

12. Jamieson WR, Edwards FH, Schwartz M, Bero JW, Clark RE, Grover FL - Risk stratification for cardiac valve replacement. National Cardiac Surgery Database. Ann Thorac Surg 1999; 67: 943-51

13. Barrozo CAM, Santos RC, Sgarbi CJ - Reoperação em valvopatias: análise de 697 pacientes. Rev Bras Cir Cardiovasc 1994, 9: 109-12.

14. Piehler JM, Blackstone EH, Bailey KR et al. - Reoperation on prosthetic heart valves: patient- specific estimates of inhospital events. J Thorac Cardiovasc Surg 1995; 109: 30-48.

15. Rizzoli G, Bottio TDE, Perini 1, Scalia D, Thiene G, Casarotto D - Multivariate analysis of survival after malfunctioning biological and mechanical prosthesis replacement. Ann Thorac Surg 1998; 66: S88-94.

16. Pansisi S, Ottino G, Forsennati PG, et al. Reoperations on heart valve prostheses: an analysis of operative risks and late results. Ann Thorac Surg 1990; 50: 590-6.

17. Husebye DG, Pluth JR, Piehler JM et al. - Reoperation on prosthetic heart valves: an analysis of risk factors in 552 patients. J Thorac Cardiovasc Surg 1983; 86: 543-52.

18. Turina J, Turina $\mathbf{M}$ - Left ventricular function and valvular reoperations. J Heart Valve Dis 1995; 4(Supl II): S223-9.

19. Akins CW, Buckley MJ, Daggett WM et al. - Risk of reoperative valve replacement for failed mitral and aortic bioprostheses. Ann Thorac Surg 1998; 65:1545-52.

20. Caus T, Mesana T, Mouly A, Guez P, Tapia M, Montiès JR Remplacements valvulaires itératifs; prognostic et résultats. Arch Mal Coeur Vaiss 1995; 88: 35-41.

21. Lytle BW, Priest BP, Taylor PC et al. - Surgical treatment of prosthetic valve endocarditis. JThorac Cardiovasc Surg 1996; 111: 198-210.

22. Pomerantzeff PMA, Brandão CMA, Mansur AJ et al. Tratamento cirúrgico do abcesso de anel valvar associado a endocardite bacteriana: resultados imediatos e tardios. Rev Bras Cir Cardiovasc 1996; 11: 259-62.

23. Cohn LH, Aranki SF, Rizzo RJ et al. - Decrease in operative risk of reoperative valve surgery. Ann Thorac Surg 1993; 56: 15-21.

24. Antunes MJ - Reoperations on cardiac valves. J Heart Valve Dis 1992; 1: 15-28. 
25. Cosgrove DM. - Evaluation of perioperative risk factors. J Card Surg 1990; 5(3): 227-30.

26. Andrade IG, Cartier R, Panisi P, Ennabli K, Grondin CM Factors influencing early and late survival in patients with combined mitral valve replacement and myocardial revascularization and in those with isolated replacement. Ann Thorac Surg 1987;44: 607-13.

27. Carabello BA, Williams H, Gash AK et al. - Hemodynamic predictors of outcome in patients undergoing valve replacement. Circulation 1986; 74: 1309-16.
28. Rossiter SJ, Miller DC, Stinson EB, Oyer PE, Reitz BA, Shumway NE - Aortic and mitral prosthetic valve reoperations: early and late results. Arch Surg 1979; 114: 1279-83.

29. Blackstone EH, Kirklin JW. - Recommendations for prophylactic removal of heart valve prostheses. J Heart Valve Dis 1992; 1: 3-14.

30. Bortolotti U, Milano A, Guerra F et al. - Failure of Hancock pericardial xenografts: is prophylactic bioprosthetic replacement justified? Ann Thorac Surg 1991; 51: 430-7. 